\title{
Relation model describing the effects of introducing RFID in the supply chain: evidence from the food and beverage industry in South Korea
}

\author{
Oh-Keun Ha $\cdot$ Yong-Seok Song $\cdot$ Kyung-Yong Chung • \\ Kang-Dae Lee $\cdot$ Dongjoo Park
}

Received: 21 December 2012/Accepted: 15 March 2013/Published online: 8 May 2013

(C) The Author(s) 2013. This article is published with open access at Springerlink.com

\begin{abstract}
The development of information technology has rapidly changed the logistics industry. RFID has become more and more important in the context of supply chain management (SCM), and implementation of RFID in SCM brings with it the potential to manage the information flow and to support communication and collaboration along the supply chain. This study was conducted to build a relation model, which is a structural model, to identify the effects of introducing RFID into the supply chain of the food and beverage industry in Korea. The supply chain of the food and beverage industry was divided into five activities: procurement, production, transport, sale,
\end{abstract}

O.-K. Ha

Department of Management Research, Korail Research Institute, Daejeon 293-74, Korea

e-mail: okha@korail.com

\section{Y.-S. Song}

Korea Institute of Construction and Transportation Technology, Evaluation and Planning, 1600 Kwanyang-dong, Dongan-gu, Anyang-si, Gyeonggi-do, Korea

e-mail: soyoso@kictep.re.kr

\section{K.-Y. Chung}

School of Computer Information Engineering, Sangji University, 83, Sangjidae-gil, Wonju, Gangwon-do, Korea

e-mail: dragonhci@hanmail.net

K.-D. Lee $(\bowtie)$

Department of Packaging, Yonsei University, 234 Maeji

Heungup, Wonju, Kangwon-do, Korea

e-mail: pimeson@yonsei.ac.kr

D. Park

Department of Transportation Engineering, University of Seoul, 90 Jeonnong, Dongdaemun, Seoul, Korea

e-mail: djpark@uos.ac.kr warehousing, and administration. This study was based on the premise that RFID will be embedded in a transport box or pallet circulated in the SC. The model showed that SC activities have positive relationships through the RFID system, and the introduction of RFID promotes information interchanges between SC activities, which in turn enable the coordination and consolidation of a total SCM. From the results of this study, it is expected that the RFID system does not only enable the SC partners to improve their utilities but also promotes the efficiency of SCM as a whole. This is meaningful considering that there is still a controversy regarding the effects of RFID on SCM.

Keywords RFID - Supply chain management . Structural model · Food and beverage industry

\section{Introduction}

The development of information technology (IT) has rapidly changed the logistics industry. RFID is becoming more and more important in the context of supply chain management (SCM) [30]. The implementation of RFID in SCM brings with it the potential to manage the information flow and to support communication and collaboration along the supply chain (SC) [4, 22, 34]. A few empirical studies, however, have suggested that it is very difficult to ascertain the performance of RFID applications [18, 50, 52]. This phenomenon has been referred to as the "productivity paradox of IT" [31].

On the other hand, many studies supporting the premise that the implementation of RFID has significant positive effects on SCM have been reviewed by these authors. RFID serves as a key enabler for coordinating and 
integrating SCM, through the sharing of vital information regarding key SC activities both inside and outside the boundaries of material suppliers, manufacturers, wholesalers, and consumers [25]. RFID has a vast potential in terms of enabling demand forecasts and production schedules in SCM [21]. Introducing RFID into SCM will also produce direct benefits by decreasing the coordination costs, including the costs of integrated decisions, and the transaction risks, which are exploited in the relationship between the SC partners [10].

The implementation of RFID in SCM for the food and beverage industry has led to a wide range of benefits, including shrinkage reduction, reduced labor costs, and improved customer service. Food and beverage retailers, however, will have to address a number of operational challenges and consumer privacy concerns before they realize these benefits $[23,38,39]$.

Recently, the need for hygiene and safety has become a growing concern [26]. Between 1999 and 2003, the US Food and Drug Administration reported a total of 1,307 recalls of processed food products [28]. In Japan, a massive recall from two Japanese foodmakers was also reported in 2002 [20]. The implementation of RFID has been suggested as a good solution to enable tracing capability in the $\mathrm{SC}$ of the food and beverage industry [28].

This study was conducted to build a relation model, which is a structural model, to identify the effects of introducing RFID into the SC of the food and beverage industry. SC consists of six activities: procurement, production, transport, sale, warehousing, and administration. This study is based on the premise that RFID will be embedded in a transport box or pallet circulated in the SC. The remainder of this study is organized as follows. The following section presents a literature review that helps underpin the research framework, and the study's hypotheses. The research methodology is presented in the Sect. 3. The results and discussion are presented in Sect. 4, followed by the Sect. 5 .

\section{Literature review and hypotheses}

\subsection{Research framework}

The purpose of implementing RFID is to eliminate the uncertainty in forecasting the demand and to secure visibility and traceability in SCM. There are a number of key issues in the implementation of RFID in SCM, which has a complex relationship with production, procurement, transport, sale, warehousing, and administration [30]: (1) the technical standards have not been finalized; (2) the business benefits or returns are unclear; and (3) there is a lack of industry-wide adoption. It has been suggested that RFID implementation has the potential to improve a firm's financial performance $[5,11,35]$.

In terms of its applicability to the grocery SC, two opposing opinions have been presented. The first is that the use of RFID offers numerous advantages over bar codes and presents possible benefits $[1,7,9,17]$. On the other hand, the second view emphasizes the cost of the technology and argues that the attainable benefits are unlikely to offset the high capital investment required [6, 43].

IT serves as a key enabler of the SC through the sharing of vital information both inside and outside an organization's boundaries [10, 25, 48]. RFID plays an important role in coordinating and consolidating the SC. The research framework developed in this study and presented in Fig. 1 proposes that introducing RFID into the SC will enable the operational performance of SCM. The framework also considers the direct impacts of RFID in relation to procurement, production, transport, sale, warehousing, and administration. Based on the literature, hypotheses were developed with respect to the proposed relationships among the six SC components presented in Fig. 1.

\subsection{Hypotheses development}

Information technologies, including RFID, play critical roles in SCM activities [24] and provide benefits to companies by fostering value-added partnerships between the SC partners [19, 40, 44]. The administrators involved in the coordination of information, materials, and data flow have been affected by the introduction of RFID into SCM. RFID makes agents, who are SCM components, play roles in the transmission of information and in the judgment of the logical conditions. The member structure of the SC consists of several levels, including components suppliers, manufacturers, distribution centers, warehouses, retailers, and customers [45].

Food-processing plant managers can use handheld PCs to send data obtained from anywhere in the plant, for the purpose of quality inspection [36]. RFID will enable them to manage food production with the correct data and to monitor bacterial concentration in the food products [37]. With the application of RFID in SCM, United Biscuits reported improved efficiency in its production process, improved information accuracy, better tracking of its food products, and a decline in the incidence of errors. Ford Motor Company uses RFID to ensure the accurate and efficient routing and identification of its vehicles through an automated production process [41].

The advantages of the usage of RFID in SCM are as follows [32]. First, the warehouse and stockroom inventories can be monitored more accurately, and replenishment orders 
Fig. 1 Research framework

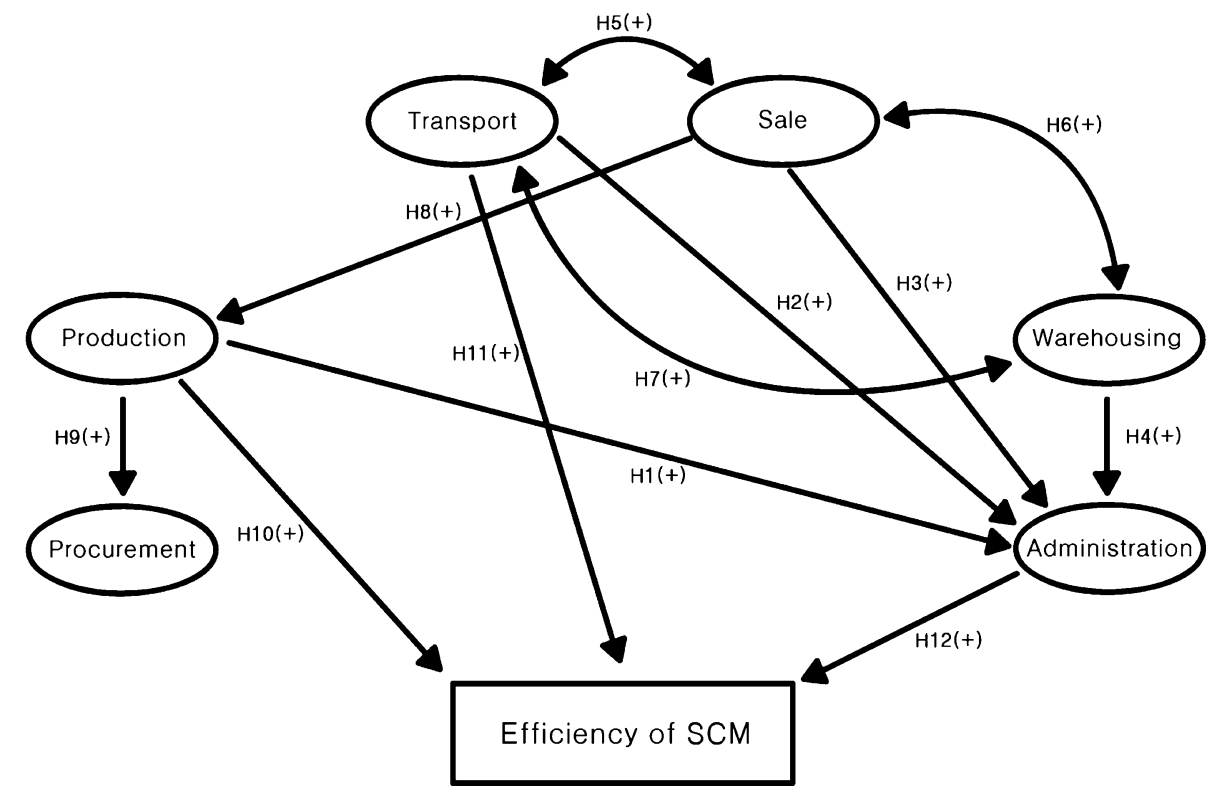

can be issued more quickly. Second, the inventory in warehouses, stockrooms, and store shelves will become more visible and trackable. Third, less storage space is needed, thus reducing warehousing and handling costs. Unilever showed that its information regarding the movements of physical loads (handled by pallets) has become more reliable when RFID began to be used in its warehouses. Chevrolet Creative Services uses an RFID system to support the shipments of goods that come in and go out of its warehouse, which it reports has reduced human-caused errors, has produced significant time savings, and, over time, has eliminated emergency shipping charges [41]. The introduction of RFID has led to an $85 \%$ reduction in costs related to administration and paperwork, an $8 \%$ reduction in warehousing costs, and a $15 \%$ reduction in replenishment costs [8]. Stock loss reduction was due to increased inventory accuracy and better control of stock rotation [27, 33].

Based on the results of the aforementioned studies, the following hypotheses were formulated:

H1 The introduction of RFID into the production process will produce positive effects on administration.

H2 The introduction of RFID into transport (covered distribution) will produce positive effects on administration.

H3 The introduction of RFID into sales management will produce positive effects on administration.

H4 The introduction of RFID into warehousing (covered inventory) management will produce positive effects on administration.

The information generated in the sales process will be sent to the production management [12]. The production volume can be ordered and controlled based on the real- time sales and inventory volume information. In addition, the stock management cost can be reduced, and the production volume can be forecasted using the sales volume information [3, 47]. The introduction of RFID into SCM led to reduced production costs due to automated invoice and inventory traceability [35, 46]. The RFID sensor tag can be queried for food safety and information, allowing instant product traceability. It is suggested that the inventory and transport be managed and planned based on this traceability [51]. The benefits of the introduction of RFID into SCM are the availability of real-time information, increased inventory visibility, stock-out reduction, realtime access to and update of the current store inventory levels, and automated proof of delivery [14].

Based on the foregoing, the following hypotheses were formulated:

H5 The introduction of RFID will establish a positive relationship between transport and the sale process.

H6 The introduction of RFID will establish a positive relationship between sales and warehousing management.

H7 The introduction of RFID will establish a positive relationship between warehousing management and transport.

H8 The introduction of RFID in the sales process will produce positive effects on production management.

H9 The introduction of RFID in production will produce positive effects on procurement management.

RFID has a vast potential to facilitate integration and coordination among the SC partners by enabling the sharing of information regarding the demand forecasts and 
production schedules that dictate the SC activities [21]. By using RFID, food traceability can be accomplished, enabling the tracing and following of food, feeds, and foodproducing animals throughout the production and distribution process. Cheese manufacturers are able to trace the product along the SC with great precision [42]. The introduction of RFID has reduced the labor associated with performing inventory counts of shelved goods, has improved theft prevention, and has enabled better control of the entire SC [7]. Additional benefits can thus be derived from real-time information availability, data sharing through the whole SC, and improved visibility [12]. The implementation of RFID will also help improve the decisions related to stock replenishment through the availability of more accurate inventory information, thus improving the SC performance [29].

Accordingly, the following hypotheses are proposed:

H10 The introduction of RFID into the production process will produce positive effects on the efficiency of SCM.

H11 The introduction of RFID into transport will produce positive effects on the efficiency of SCM.

H12 The introduction of RFID into administration will produce positive effects on the efficiency of SCM.

\section{Research methodology}

\subsection{Sample and data collection}

A survey was carried out to investigate the impact of the introduction of RFID into SCM. The questionnaires were distributed to 240 food and beverage enterprises whose main products are bottled beverages, biscuits, and meat/ marine processed foods. It was requested that the questionnaire be completed by the senior officer/executive in charge of SCM. Surveys were also conducted by telephone, fax, and e-mail, and a total of 167 accomplished questionnaires were returned. The overall response rate was $69.6 \%$ (167/240), which was considered satisfactory for subsequent analysis. Twenty-one variables describing SCM (i.e., procurement, production, transport, sale, warehousing, administration, and efficiency) were used. These observable variables were defined as follows (see Table 1).

\subsection{Measurement of variables}

The research framework, based on the literature, consisted of six parts: procurement, production, transport, sale, warehousing, and administration. The 21 variables were divided into six categories, as shown in Table 1. The
Table 1 Definitions of observable variables

\begin{tabular}{lll}
\hline No. & Name of var. & Definition of observable variable \\
\hline 1 & Mate1 & Accuracy of orders for the demand of material \\
2 & Mate2 & Accuracy of time for the demand of material \\
3 & Prod1 & Prevention of defective, forged, and missing products in production \\
4 & Prod2 & Accurate management of production and inventory \\
5 & Prod3 & Real-time inventory management for material \\
6 & Prod4 & Management of period of circulation for products \\
7 & Tran1 & Accuracy of transport \\
8 & Tran2 & Traceability of transport \\
9 & Sale1 & Reduction in product returns after sale \\
10 & Sale2 & Ease of recall after sale \\
11 & Sale3 & Ease of establishing sale strategies based on consumption patterns \\
12 & Ware1 & Reduction in inspection time for warehoused materials \\
13 & Ware2 & Reduction in load/unload time for warehoused materials \\
14 & Ware3 & Reduction in inspection time for warehoused products \\
15 & Ware4 & Reduction in load/unload time for warehoused products \\
16 & Admi1 & Increase in productivity through work process improvements \\
17 & Admi2 & Enhancement of decision making and response capability \\
18 & Admi3 & Promotion of cooperation between partners in SCM, and capability of market response \\
19 & Admi4 & Enhancement of consumer service \\
20 & Admi5 & Reduction in administrative costs \\
21 & Efficiency & Efficiency of SCM, including procurement, production, transport, sale and warehousing
\end{tabular}


respondents were asked to indicate the observable variables in the six categories that affect the operational performance of SCM, relying on a five-point scale ranging from " $1=$ of no importance" to " 5 = of major importance." The results of the descriptive statistical analysis of the 21 variables are shown in Table 2 .

\section{Results and discussion}

\subsection{Exploratory factor analysis}

Exploratory factor analysis (EFA) was conducted to draw the factors' structure, with 21 observatory variables, to confirm such variables' reliability and to eliminate the inadequate observatory variables. EFA was conducted prior to confirmatory factor analysis (CFA). After EFA, the deduced factors were defined as patent variables [16]. EFA with oblique rotation (direct oblique) and factor extraction with maximum-likelihood estimation were performed [15]. Six factors were extracted from EFA, which could explain $77.58 \%$ of the overall variation and which were statistically significant with respect to the $p$ value and RMSEA. Cronbach's alpha was also over 0.6, implying the credibility of the selected variables (Tables 3,4 ).

\subsection{Confirmatory factor analysis}

Confirmatory factor analysis was conducted to confirm the unidimensionality of the observable variables as it can do so more accurately than EFA can [15]. It was confirmed that all the observable variables included in the six patent variables could be statistically accepted. The CFA technique is based on the comparison of the variance-covariance matrix obtained from the sample to form the model [13]. The technique is quite sensitive to the sample size, and it is recommended that several cases be considered per free parameter [2].

\subsection{Structural equation modeling}

The Amos 6.0 program was used to clarify the impact of introducing RFID into the SCM of the food and beverage industry. The goodness-of-fit indices for the research framework were RMSEA, GFI, TLI, and CFI. These indices conform to the normal acceptable standards. The program is excessively sensitive to the sample size, however, and therefore has a bias toward rejecting the null hypothesis. The value of the $\chi^{2} / d f$ ratio was 2.392 . This ratio should be within the range of $0-5$, with the lower values indicating a better fit. In addition, GFI, TLI, and CFI for the research framework are highly satisfactory as they
Table 2 Summary measurement results

\begin{tabular}{llllll}
\hline Latent variables & Observable variables & Mean & SD & Skewness & Kurtosis \\
\hline Procurement & Mate1 & 3.2096 & 1.08012 & -0.514 & -0.252 \\
Production & Mate2 & 3.1796 & 1.03729 & -0.531 & -0.125 \\
& Prod1 & 3.0958 & 1.06600 & -0.514 & -0.110 \\
& Prod2 & 2.9162 & 1.06339 & -0.176 & -0.407 \\
Transport & Prod3 & 3.1617 & 1.08558 & -0.298 & -0.397 \\
\multirow{3}{*}{ Sale } & Prod4 & 3.5150 & 1.00926 & -0.663 & -0.012 \\
& Tran1 & 3.3054 & 0.97053 & -0.410 & -0.152 \\
& Tran2 & 3.3593 & 1.03384 & -0.485 & -0.238 \\
Warehousing & Sale1 & 2.9401 & 1.02793 & -0.182 & -0.591 \\
& Sale2 & 3.2395 & 1.02505 & -0.496 & -0.117 \\
& Sale3 & 2.9641 & 1.01133 & -0.316 & -0.446 \\
& Ware1 & 3.2515 & 0.99225 & -0.229 & -0.326 \\
Efficiency of SCM & Ware2 & 3.0419 & 0.099003 & -0.198 & -0.490 \\
\hline \multirow{3}{*}{ Administration } & Ware3 & 3.2096 & 1.00500 & -0.324 & -0.436 \\
& Ware4 & 3.1138 & 0.99043 & -0.344 & -0.424 \\
& Admi1 & 3.2695 & 0.92122 & -0.563 & 0.280 \\
& Admi2 & 3.3653 & 0.95286 & -0.538 & 0.164 \\
& Admi3 & 3.2814 & 0.91761 & -0.448 & 0.270 \\
& Admi4 & 3.2934 & 0.92039 & -0.524 & 0.215 \\
& Admi5 & 3.2036 & 0.99722 & -0.493 & 0.002 \\
& & 3.3174 & 0.83935 & -0.139 & -0.139 \\
\hline
\end{tabular}


Table 3 Results of EFA and credibility analysis

\begin{tabular}{|c|c|c|c|c|c|c|c|}
\hline \multirow[t]{2}{*}{ Observable variables } & \multicolumn{6}{|c|}{ Latent variables } & \multirow[t]{2}{*}{ Cronbach's alpha } \\
\hline & Procurement & Transport & Warehousing & Production & Sale & Administration & \\
\hline Mate1 & 0.989 & & & & & & 0.954 \\
\hline Mate2 & 0.853 & & & & & & 0.954 \\
\hline Tran1 & & 0.947 & & & & & 0.886 \\
\hline Tran2 & & 0.589 & & & & & 0.886 \\
\hline Ware1 & & & 0.950 & & & & 0.931 \\
\hline Ware2 & & & 0.919 & & & & 0.931 \\
\hline Ware3 & & & 0.798 & & & & 0.931 \\
\hline Ware4 & & & 0.648 & & & & 0.931 \\
\hline Prod1 & & & & 0.948 & & & 0.889 \\
\hline Prod2 & & & & 0.880 & & & 0.889 \\
\hline Prod3 & & & & 0.579 & & & 0.889 \\
\hline Prod4 & & & & 0.514 & & & 0.889 \\
\hline Sale1 & & & & & 0.952 & & 0.899 \\
\hline Sale2 & & & & & 0.726 & & 0.899 \\
\hline Sale3 & & & & & 0.607 & & 0.899 \\
\hline Admi1 & & & & & & -0.869 & 0.934 \\
\hline Admi2 & & & & & & -0.801 & 0.934 \\
\hline Admi3 & & & & & & -0.707 & 0.934 \\
\hline Admi 4 & & & & & & -0.699 & 0.934 \\
\hline Admi5 & & & & & & -0.695 & 0.934 \\
\hline Eigenvalue & 7.602 & 1.289 & 3.483 & 1.452 & 0.957 & 0.731 & - \\
\hline$\%$ of variance & 38.01 & 6.443 & 17.41 & 7.262 & 4.787 & 3.656 & - \\
\hline Cumulative $\%$ & 38.01 & 44.45 & 61.87 & 69.13 & 73.92 & 77.57 & - \\
\hline$\chi^{2}$ & 149.158 & & & & & & \\
\hline Sig. & 0.000 & & & & & & \\
\hline RMSEA & 0.067 & & & & & & \\
\hline
\end{tabular}

are very close to the value of 1.0 , which denotes a perfect fit. The results show that the model developed in this study fits this criterion and attests to the construct validity for the measurement of the developed model. The results of the structural equation model related to hypotheses 1-12 are shown in Fig. 2 and Table 5. With the exception of H3, each hypothesis is significant $(p<0.05)$. This is contrary to the results of the previous studies, in which the effects of introducing RFID could not be specified [1, 7, 9, 17]. It was found in this study, however, that the benefits of introducing RFID into the SC could be measured in a special sector, such as the food and beverage industry. The results for the other hypotheses are as follows.

The results for $\mathrm{H} 1, \mathrm{H} 2$, and $\mathrm{H} 4$ show that the information from production, transport, and warehousing can be used to make a rational decision [21, 32] and can produce benefits in administration [8, 29, 42]. The results for $\mathrm{H} 5, \mathrm{H} 6$, and $\mathrm{H} 7$ show that the positive relationships between transport, sale, and warehousing promoted through RFID lead to the building of a more efficient SCM [32, 45] and help cut down the costs related to the personnel and materials [7]. The results for $\mathrm{H} 8$ and $\mathrm{H} 9$ show that real-time information flows from sale to production, which includes information regarding the volume and time of sale, enabling the management of the production and warehousing schedule. This information flows from production to procurement, which includes the volume and time of material demands, leading to the improved efficiency of material procurement [3, 7, 12, 42]. The results for $\mathrm{H} 10, \mathrm{H} 11$, and $\mathrm{H} 12$ indicate that real-time information from production, transport, and administration affects the efficiency of SCM [7, 8, 21, 32, 49]. Based on these results, it is suggested that the implementation of RFID produced positive effects on SCM, such as by providing traceability and visibility therein, reducing the costs due to the relationship between the SC partners, advancing the relationship between the SC partners, and improving the performance of all the SC activities. 
Table 4 Results of CFA

\begin{tabular}{|c|c|c|c|c|c|}
\hline Latent variables & Observable variables & Unstandardized weights & Standardized weights & Standard error & $t$ Value \\
\hline \multirow[t]{2}{*}{ Procurement } & Mate1 & 1.00 & 0.995 & - & - \\
\hline & Mate2 & 0.953 & 0.968 & 0.033 & 29.317 \\
\hline \multirow[t]{4}{*}{ Production } & Prod1 & 1.00 & 0.741 & - & - \\
\hline & Prod2 & 1.241 & 0.922 & 0.101 & 12.231 \\
\hline & Prod3 & 1.260 & 0.917 & 0.104 & 12.168 \\
\hline & Prod4 & 0.901 & 0.706 & 0.098 & 9.158 \\
\hline \multirow[t]{2}{*}{ Transport } & Tran1 & 1.00 & 0.756 & - & - \\
\hline & Tran2 & 1.212 & 0.861 & 0.120 & 10.128 \\
\hline \multirow[t]{3}{*}{ Sale } & Sale1 & 1.00 & 0.858 & - & - \\
\hline & Sale2 & 1.011 & 0.870 & 0.072 & 14.088 \\
\hline & Sale3 & 0.992 & 0.865 & 0.071 & 13.981 \\
\hline \multirow[t]{4}{*}{ Warehousing } & Ware1 & 1.00 & 0.819 & - & - \\
\hline & Ware2 & 1.093 & 0.897. & 0.076 & 14.339 \\
\hline & Ware3 & 1.095 & 0.885 & 0.078 & 14.037 \\
\hline & Ware4 & 1.119 & 0.917 & 0.075 & 14.840 \\
\hline \multirow[t]{5}{*}{ Administration } & Admi1 & 1.00 & 0.871 & - & - \\
\hline & Admi2 & 1.88 & 0.916 & 0.063 & 17.301 \\
\hline & Admi3 & 1.031 & 0.902 & 0.062 & 16.735 \\
\hline & Admi4 & 0.963 & 0.839 & 0.066 & 14.491 \\
\hline & Admi5 & 0.965 & 0.777 & 0.076 & 12.626 \\
\hline
\end{tabular}

$\chi^{2} / d f=2.377$, RMSEA $=0.091, \mathrm{GFI}=0.906, \mathrm{TLI}=0.918, \mathrm{CFI}=0.933$

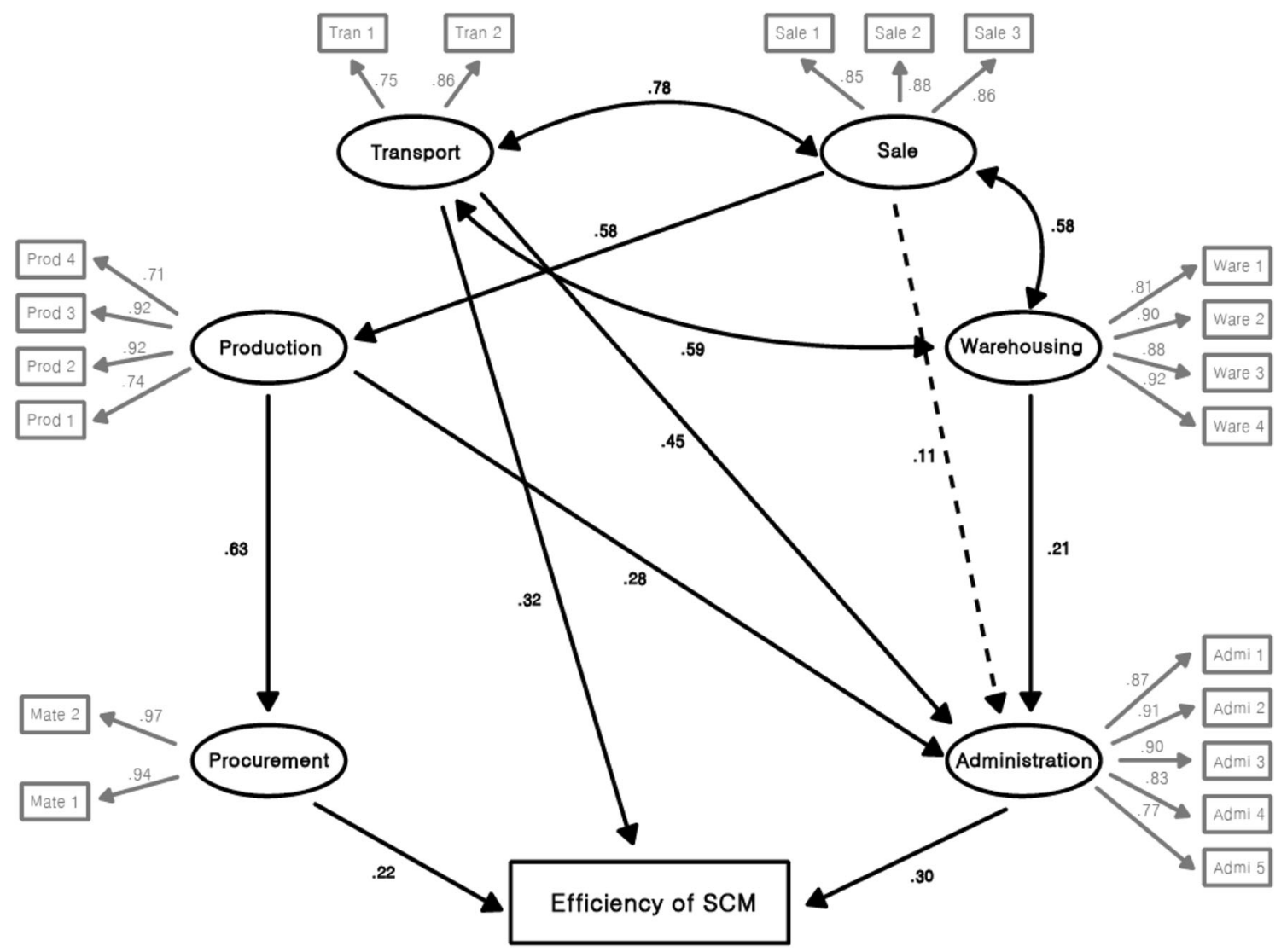

Fig. 2 Results of structural equation modeling. $\chi^{2} / d f=2.392$, RMSEA $=0.092$, GFI $=0.997$, TLI $=0.908$, CFI $=0.922$ 
Table 5 Results of structural equation modeling

\begin{tabular}{|c|c|c|c|c|}
\hline Hypotheses & Paths & Unstandardized weights & Standardized weights & $t$ value \\
\hline H1 & Production $\rightarrow$ administration & 0.213 & 0.279 & 4.342 \\
\hline $\mathrm{H} 2$ & Transport $\rightarrow$ administration & 0.384 & 0.448 & 3.618 \\
\hline $\mathrm{H} 3$ & Sale $\rightarrow$ administration & 0.099 & 0.113 & 0.979 \\
\hline $\mathrm{H} 4$ & Warehousing $\rightarrow$ administration & 0.172 & 0.207 & 3.051 \\
\hline H5 & Transport $\leftrightarrow$ sale & 0.599 & 0.784 & 6.691 \\
\hline H6 & Sale $\leftrightarrow$ warehousing & 0.456 & 0.578 & 5.785 \\
\hline $\mathrm{H} 7$ & Warehousing $\leftrightarrow$ transport & 0.476 & 0.592 & 5.727 \\
\hline $\mathrm{H} 8$ & Sale $\rightarrow$ production & 0.660 & 0.575 & 7.370 \\
\hline H9 & Production $\rightarrow$ procurement & 0.634 & 0.629 & 8.989 \\
\hline H10 & Production $\rightarrow$ efficiency & 0.181 & 0.220 & 2.906 \\
\hline H11 & Transport $\rightarrow$ efficiency & 0.296 & 0.319 & 2.662 \\
\hline $\mathrm{H} 12$ & Administration $\rightarrow$ efficiency & 0.319 & 0.295 & 2.306 \\
\hline
\end{tabular}

\section{Conclusion}

In this study, a relation model, which is a structural model for identifying the effects of introducing RFID to the SCM of the food and beverage industry, was empirically built. The effects were clarified using the developed model. The model showed that $\mathrm{SC}$ activities have positive relationships through the RFID system. The introduction of RFID promotes information interchanges between SC activities, which in turn enable the coordination and consolidation of a total SCM. Ultimately, the RFID system does not only enable the SC partners to improve their utilities but also promotes the efficiency of SCM as a whole. This is a meaningful result considering that there is still a controversy regarding the effects of RFID on SCM. The findings of this study can thus contribute to a deeper understanding of the impact of RFID implementation on SCM and highlight the need for decision makers to introduce RFID into SCM as an enabler.

Open Access This article is distributed under the terms of the Creative Commons Attribution License which permits any use, distribution, and reproduction in any medium, provided the original author(s) and the source are credited.

\section{References}

1. Ashton K (2000) Internet things-MIT, embedded technology and the next international revolution, paper presented at the Tag 2000. Baltic Conventions, The Commonwealth Conference \& Events Centre, London, 25 May

2. Bollen KA (1989) Structural equation with latent variables. Wiley, New York

3. Bergeron F, Gingras L, Hadaya P, Caron C (2005) A framework for evaluating strategic location-based applications in business. In: Proceedings of the 38th Hawaii international conference on system sciences, pp 1-8
4. Bharadwaj A, Bharadwaj SG, Konsynski BR (1999) Information technology effects on firm performance as measured by Tobin's q. Manage Sci 45(July):1008-1025

5. Bharadwaj A (2000) A resource-based perspective on information technology capability and firm performance: an empirical investigation. MIS Quarterly 24(1):169-196

6. Burnell J (1999) Users will overcome many obstacles and implement RFID, study predicts. Autom ID News 15(5):26

7. Bushnell R (2000) RFID's wide range of possibilities. Mod Mater Handl 142(1):288A-K

8. Chappell G, Durdan D, Gilbert G, Ginsburg, L, Smith J, Tobolski J (2003) Auto-ID on delivery: the value of Auto-ID technology in the retail supply chain. Auto-ID Center

9. Chamberlain G (1997) Shopping become a 'smart' experience. Available at: http://www.designnews.com/document.asp?doc_id $=214601$. Accessed 17 Mar 2013

10. Clemons E, Reddi S, Row M (1993) The impact of information technology in the organization of economic activity: the 'move to the middle' hypothesis. J Manag Inf Syst 10(2):9-35

11. Dehning B, Richardson VJ, Zmud RW (2006) The financial performance effects if IT-based supply chain management systems in manufacturing firms. J Oper Manag 25(4):806-824

12. Eleonora B, Antonio R (2008) Economical assessment of the impact of RFID technology and EPC system on the fast-moving consumer goods supply chain. Int J Prod Econ 112(2):548-569

13. Erkan B, Mehmet D, Ekrem T, Halil Z (2009) A causal analysis of the impact of information systems and supply chain management practices on operational performance: evidence from manufacturing SMEs in Turkey. Int J Prod Econ 122(1):133-149

14. Fernie J (1994) Quick response: an international perspective. Int J Phys Distrib Logist Manag 24(6):38-46

15. Gerbing DW, Anderson JC (1988) An updated paradigm for scale development incorporating unidimensionality and its assessment. J Mark Res 25(2):186-192

16. Gerbing DW, Hamilton JD (1996) Viability of exploratory factor analysis as a precursor to confirmatory factor analysis. Struct Eq Model 3(1):62-72

17. Hawkes P (1994) Supertag-stock counting off its trolley. Sens Rev 14(3):23-26

18. Hitt LM, Brynjolfsson E (1996) Productivity, business profitability, and consumer surplus: three different measures of information technology value. MIS Quarterly 20(2):121-142

19. Holland C, Lockett G, Blackman L (1992) Planning for electronic data interchange. Strateg Manag J 13(1):539-550 
20. Jiji Press English News Service (2003) Wire feed. Tokyo, June 3, 1

21. Karoway C (1997) Superior supply chains pack plenty of byte. Purch Technol 8(11):32-35

22. Katayama H, Bennett D (1999) Agility, adaptability and leanness: a comparison if concepts and a study of practice. Int J Prod Econ 60-61:43-51

23. Katerian M, Michael S, Sherali Z, Zakaria M (2012) User-driven RFID applications and challenges. Pers Ubiquit Comput 16 (3):225-234

24. Kearns GS, Lederer AL (2003) A resource-based view of strategic IT alignment: how knowledge sharing creates competitive advantage. Decis Sci 34(1):1-29

25. Kelle P, Akbulut A (2005) The role of ERP tools in supply chain information sharing, cooperation, and cost optimization. Int $\mathbf{J}$ Prod Econ 93-94:41-52

26. Kerry JP, O'Grady MN, Hogan SA (2006) Past, current and potential utilization of active and intelligent packaging systems for meat and muscle-based products: a review. Meat Sci 74 (1):113-130

27. Kim KS, Kim MS (2012) RFID-based location-sensing system for safety management. Pers Ubiquit Comput 16(3):235-243

28. Kumar S, Budin EM (2006) Prevention and management of product recalls in the processed food industry: a case study based in an exporter's perspective. Technovation 26(5-6):739-750

29. Lee YM, Chen F, Leung YT (2004) Exploring the impact of RFID on supply chain dynamics. In: Proceedings if the 2004 winter simulation conference, pp 1145-1152

30. Li S, Visich JK, Khumawala BM, Zhang C (2006) Radio frequency identification technology: applications, technical challenges and strategies. Sens Rev 26(3):193

31. Lim JH, Richadson VJ, Roberts TL (2004) Information technology investment and firm performance: a meta-analysis. In: Proceedings of the 37th Hawaii international conference on systems science, pp 1-11

32. Loebbecke C, Palmer J (2006) RFID in the fashion industry: Kaufhof Department Stores AG and Gerry Weber International AG, fashion manufacturer. MIS Quarterly Executive 5(2):15-25

33. Mikko K (2003) Increasing efficiency in the supply chain for short shelf life goods using RFID tagging. Int J Retail Distrib Manag 31(10):529-536

34. Mondragon AEC, Lyons AC, Kehoe DF (2004) Assessing the value of information systems in supporting agility in high-tech manufacturing enterprises. Int J Oper Prod Manag 24(12):12191246

35. Mukhopadhyay T, Kekre S, Kalathur S (1995) Business value of information technology: a study of electronic data interchange. MIS Quarterly 19(2):137-156

36. Najjar LJ, Thompson JC, Ockerman J (1997) Wearable computer for quality assurance inspectors in a food processing plant. In: Proceedings of the 1st IEEE international symposium on wearable computers, Cambridge, Massachusetts, USA, October 13-14, pp 163-164

37. Ong KG, Puckett LG, Sharma BV, Loiselle M, Grimes CA, Craig A, Bachas LG (2001) Wireless, passive, resonant-circuit sensors for monitoring food quality. In: Proceedings of SPIE-the international society for optical engineering, 4575, Boston, MA. USA, October 28-November 2, pp 150-159

38. Pedro PL, Agustin O, Esther P, Julio C (2012) A secure distancebased RFID identification protocol with an off-line back-end database. Pers Ubiquit Comput 16(3):351-365

39. Peter J, Colin CH, Daphne C (2005) Radio frequency identification and food retailing in the UK. British Food J 107(6):356360

40. Ragatz GL, Handfield RB, Scannell TV (1997) Success factors for integrating suppliers into new product development. J Prod Innov Manage 14(1):190-202

41. Rebecca A (2005) RFID technologies: supply-chain applications and implementation issues. Inf Syst Manag Winter 22(1):51-65

42. Regattieri A, Gamberi M, Manzini R (2007) Traceability of food products: general framework and experimental evidence. J Food Eng 81(2):347-356

43. Riso F (2001) Intelligent chip technology - an RFID update, paper presented at the InTelligent supply Chain. CIES-The Food Business Forum, 4-5 October, Hotel Okusa, Amsterdam

44. Scheomber HS (1992) EDI-induced redesign of coordination in logistics. Int J Phys Distrib Logisti Manag 22(8):4-14

45. Shu-Jen W, Shih-Fei L, Wei-Ling W (2007) The simulated impact of RFID-enabled supply chain on pull-based inventory replenishment in TFT-LCD industry. Int J Prod Econ 112(2):570586

46. Subramani M (2004) How do suppliers benefit from information technology use in supply chain relationship? MIS Quarterly 28 (1):45-73

47. Tomas SL, Damith CR, Mark H, Ducan MF (2012) Adding sense to the internet of things. Pers Ubiquit Comput 16(3):291-308

48. Vickery SK, Calantone R, Dròge C (1999) Supply chain flexibility: an empirical study. J Supply Chain Manag 14(3):16-24

49. Wal-Mart Facts (2005) Wal-Mart corporate communications: Wal-Mart improves on-shelf availability through the use of electronic product codes. October 14. < http://www.walmartfacts. com/newsdesk/article.aspx ?id $=1401>$

50. Weill P (1992) The relationship between investment in information technology and firm performance: a study of the value manufacturing sector. Inf Syst Res 3(4):307-333

51. Wentworth SM (2003) Microbial sensor tags. In: The 2003 IFT (The Institute of Food Engineering) annual meeting book of abstracts, Chicago, Illinois, USA, July 12-16

52. Yosri A (1992) The relationship between information technology expenditures and revenue contributing factors in large corporations. Doctoral dissertation, Walden University, Minneapolis, MN 